Production, Manufacturing and Logistics

\title{
Stability and monotonicity in newsvendor situations
}

\author{
Ulaş Özen $^{\mathrm{a}, *}$, Nesim Erkip ${ }^{\mathrm{b}}$, Marco Slikker ${ }^{\mathrm{c}}$ \\ ${ }^{a}$ Alcatel-Lucent Bell Laboratories, Blanchardstown Industrial Park, Blanchardstown, Dublin 15, Ireland \\ ${ }^{\mathrm{b}}$ Department of Industrial Engineering, Bilkent University, Ankara, Turkey \\ ${ }^{\mathrm{c}}$ School of Industrial Engineering, Eindhoven University of Technology, P.O. Box 513, 5600 MB Eindhoven, The Netherlands
}

\section{A R T I C L E I N F O}

\section{Article history:}

Received 3 February 2011

Accepted 8 November 2011

Available online 17 November 2011

\section{Keywords:}

Inventory centralization

Newsvendor

Game theory

Core

\begin{abstract}
A B S T R A C T
This study considers a supply chain that consists of $n$ retailers, each of them facing a newsvendor problem, and a supplier. Groups of retailers might increase their expected joint profit by joint ordering and inventory centralization. However, we assume that the retailers impose some level of stock that should be dedicated to them. In this situation, we show that the associated cooperative game has a non-empty core. Afterwards, we concentrate on a dynamic situation, where several model cost parameters and the retailers' dedicated stock levels can change. We investigate how the profit division might be affected by these changes. We focus on four monotonicity properties. We identify several classes of games with retailers, where some of the monotonicity properties hold. Moreover, we show that pairs of cooperative games associated with newsvendor situations do not necessarily satisfy these properties in general, when changes in dedicated stock levels are in concern.
\end{abstract}

(c) 2011 Published by Elsevier B.V.

\section{Introduction}

In this paper, we consider a distribution system that consists of a supplier and $n$ independent retailers, each facing a stochastic demand. Each retailer solves a single period problem (newsvendor problem), i.e., at the start of the period, every retailer determines his order quantity that maximizes his expected profit anticipating that, after the products are delivered to the retailers, demands are realized and satisfied from the stock as much as possible. In this network, we study the inventory pooling coalitions in which the retailers can jointly invest in a common pool of inventory to be allocated after demand realization. In a specific cooperation scenario, we study the stability of these coalitions in static and dynamic settings.

Benefits of inventory pooling, i.e., cost savings and profit increase, have been studied in different inventory settings (Eppen, 1979; Eppen and Schrage, 1981; Chen and Lin, 1989; Chang and Lin, 1991; Cherikh, 2000). These early studies assume single ownership of the system. Individual firms, however, are especially interested in what they can get for themselves from inventory centralization. Several other papers have investigated the allocation of benefits (reduced cost or increased profit) problem and proposed several mechanisms. For instance, Gerchak and Gupta (1991) compared four simple allocation mechanisms and showed that only one of them guarantees lower cost for every store than its

\footnotetext{
* Corresponding author.

E-mail addresses: ulas.ozen@alcatel-lucent.com (U. Özen), nesim@bilkent.edu.tr (N. Erkip), m.slikker@tue.nl (M. Slikker).
}

stand-alone cost. Robinson (1993) extended their analysis to other allocation mechanisms, i.e., the Shapley value (cf. Shapley, 1953) and the Lounderback allocation (Lounderback, 1976). Hartman and Dror (1996) examined allocation mechanisms for this setting using three criteria. These are core non-emptiness, computational ease and justifiability. The core concept, a measure of stability, has also received special interest by several other papers and the core non-emptiness has been shown for different newsvendor settings: newsvendors with a common pool of inventory (Hartman et al., 2000; Müller et al., 2002; Slikker et al., 2001), and newsvendors with lateral transshipment or multiple channels of supply (Slikker et al., 2005; Özen et al., 2008; Chen and Zhang, 2009). All of these studies assume complete pooling of inventory, i.e., inventory can be diverted to satisfy demand that creates the highest profit from any stock point. However, the benefits of pooling of stock can also be seen in restrictive settings. Anupindi et al. (2001) considered a distribution system where the retailers keep local inventory. After satisfying their local demand, the retailers cooperate by transshipping excess inventory in one location to satisfy excess demand in another location. They derived a profit sharing mechanism based on dual prices of the optimal shipping problem after demand realization, which is a core element and leads to joint optimal orders being an equilibrium. The model of Anupindi et al. (2001) is extended in several directions by Granot and Sošić (2003) and Sošić (2006).

In this paper, we do not consider a complete consolidation of inventories when the retailers cooperate. Instead, we assume that the retailers invest in a common pool of inventory but each retailer asks a minimum amount of inventory to be dedicated for him, 
which will be utilized if the demand in his market appears to be good. However, in case of low demand realization, the retailers release not needed inventory for other retailers' use. There could be several possible reasons for the retailer to impose such minimum level of dedicated inventories:

- Ensure income from operations: In a high selling session, it is a main tendency of a cooperation to provide the more profitable markets with the majority of the available goods in order to increase total system profit. This behavior may leave the other markets with insufficient stock. To survive in the local market and preserve marketing strength, a retailer may want to stay active in the industry. A dedicated quantity guarantees the retailer to receive an income from the business to support his inside operations (instead of being compensated only at the end of the selling period) and continue to be active in the market.

- Ensure local competitive power: The retailers might be in quantity competition in their local market and require a certain level of dedicated inventory to stay competitive.

- Ensure some customer service level: Another important factor in surviving in the market is customer satisfaction. Using minimum level of dedicated inventory, the retailer can ensure a reasonable customer service level.

We are first interested in the stability of this type of cooperation and focus on the core concept as many papers in the literature (see Hartman et al., 2000; Müller et al., 2002; Slikker et al., 2001; Slikker et al., 2005; Özen et al., 2008). The core concept considers a natural criterion for stability that is each retailer should do better in the coalition than pursuing any of their alternatives, i.e., working alone or forming another coalition. In this research, we work with the core concept. However, we carry the stability notion a step further and we are interested in a stability measure that considers the effects of changes in the environment. In our case, the retailers in such coalitions will be interested in the form of the cooperation when a change in the environment occurs. The retailers should feel that they are not discriminated or deceived under such a situation. In other words, a new core distribution of the expected total profit that does not discriminate against any of the retailers with respect to the original profit division is desired. The core is a strong concept that ensures stability in the given framework, however has less to say when there is a different framework following the original. Note that distributing the total profit using a core element is strong enough for the stability of the cooperation in the changed situation as well. However, we would like to analyze some further fairness criteria, which the retailers would naturally consider knowing the new division of total profit. Even in the situation where these fairness criteria are hard to satisfy, developing an understanding is important for the continuation of the close relations, which is critical for coordinated decision making and, hence, for the success of cooperation.

In general, monotonicity notions from cooperative game theory can be used to address this issue. Several papers study monotonicity in TU-games. Megiddo (1974) and Young (1985) studied aggregate monotonicity and coalitional monotonicity, respectively. Young (1985) also showed that no core allocation mechanisms can be coalitionally monotonic on coalitional games with 5 or more players. Afterwards Housman and Clark (1998) extended this result to games with 4 players. Sasaki (1995) and Nunez and Rafels (2002) analyzed monotonicity in assignment games. None of the monotonicity properties studied above, however, covers the cases that we analyze in this paper. Ichiishi (1981) introduced three welfare criteria on the core of the games and he established necessary and sufficient conditions for the criteria to be satisfied. Two of those criteria represent a fairness argument we like to study in this paper. We discuss this issue in more detail when we introduce four monotonicity properties in Section 2.2.
The outline of the paper is as follows: Section 2.1 gives preliminaries on cooperative game theory. In Section 2.2, we introduce 4 monotonicity properties and derive several sufficient conditions. Section 3.1 introduces the newsvendor situations with dedicated stock and the associated cooperative games. Moreover, we focus on the existence of stable profit distributions, which is shown by proving that these games have non-empty cores. In Section 3.2, we investigate the cases, where the retailers' parameters for cooperation are changed, e.g., changes in the dedicated stock levels, selling prices, purchasing cost and penalty cost, which affect the outcome of the coalition. We identify two types of changes. In the first one, all retailers' parameters are changed, and in the latter single retailer's parameters are changed. We focus on the issue of whether we can find a core distribution of total profit for the new situation, which does not discriminate against any of the retailers. This issue is captured by the 4 monotonicity properties introduced in Section 2.2. In Section 3.2.1, we identify several classes of newsvendor games where two of the monotonicity properties hold regarding the changes in selling price, purchasing cost and penalty cost. In Section 3.2.2, we analyze the monotonicity properties under changes in retailers' dedicated stock levels. After providing examples that none of the properties are guaranteed to hold for cooperative games associated with newsvendor situations, we focus on a class of newsvendor games for which one of the monotonicity properties holds. We conclude our paper in Section 4 with final remarks. The proofs that are not presented in the main body of the paper can be found in the online appendix.

\section{Preliminaries and monotonicity}

\subsection{Preliminaries}

In this section, we give a brief introduction to cooperative game theory and introduce some notation. Let $N$ be a finite set of players, $N=\{1, \ldots, n\}$. A subset of $N$ is called a coalition. A function $v$, assigning a value $v(S)$ to every coalition $S \subseteq N$ with $v(\emptyset)=0$, is called a characteristic function. The value $v(S)$ is interpreted as the maximum total profit that coalition $S$ can obtain through cooperation. Assuming that the benefit of a coalition $S$ can be transferred among the players of $S$, a pair $(N, v)$ is called a cooperative game with transferable utility (TU-game). For a game $(N, v), S \subset N$ and $S \neq \emptyset$, the subgame $\left(S, v_{S}\right)$ is defined by $v_{S}(T)=v(T)$ for each coalition $T \subseteq S$.

In reality, the players are not primarily interested in benefits of a coalition but in their individual benefits that they make out of that coalition. A division is a payoff vector $y=\left(y_{i}\right)_{i \in N} \in \mathbb{R}^{N}$, specifying for each player $i \in N$ the benefit $y_{i}$. A division $y$ is called efficient if $\sum_{i \in N} y_{i}=v(N)$ and individually rational if $y_{i} \geqslant v(\{i\})$ for all $i \in N$. Individual rationality means that every player gets at least as much as what he could obtain by staying alone. The set of all individually rational and efficient divisions constitutes the imputation set:

$I(v)=\left\{y \in \mathbb{R}^{N} \mid \sum_{i \in N} y_{i}=v(N) \quad\right.$ and $\quad y_{i} \geqslant v(\{i\}) \quad$ for each $\left.i \in N\right\}$.

If these rationality requirements are extended to all coalitions, we obtain the core:

$$
\begin{aligned}
& \operatorname{Core}(v)=\left\{y \in \mathbb{R}^{N} \mid \sum_{i \in N} y_{i}=v(N)\right. \text { and } \\
& \left.\sum_{i \in S} y_{i} \geqslant v(S) \text { for each } S \subseteq N\right\} .
\end{aligned}
$$

Thus, the core consists of all imputations in which no group of players has an incentive to split off from the grand coalition $N$ and form a smaller coalition, because they collectively receive at least as much as what they can obtain by cooperating on their own. Note that the core of a game can be empty. 
Bondareva (1963) and Shapley (1967) independently made a general characterization of games with a non-empty core by the notion of balancedness. Let us define the vector $e^{S}$ for all $S \subseteq N$ by $e_{i}^{S}=1$ for all $i \in S$ and $e_{i}^{S}=0$ for all $i \in N \backslash S$. A map $\kappa: 2^{N} \backslash\{\emptyset\} \rightarrow[0,1]$ is called a balanced map if $\sum_{S \in 2^{N} \backslash\{\emptyset\}} \kappa(S) e^{S}=e^{N}$. Further, a game $(N, v)$ is called balanced if for every balanced map $\kappa: 2^{N} \backslash\{\emptyset\} \rightarrow[0,1]$ it holds that $\sum_{S \in 2^{N} \backslash\{\emptyset\}} \kappa(S) v(S) \leqslant v(N)$. The following theorem is due to Bondareva (1963) and Shapley (1967).

Theorem 1. Let $(N, v)$ be a TU-game. Then Core $(v) \neq \emptyset$ if and only if $(N, v)$ is balanced.

A TU-game $(N, v)$ is called totally balanced if it is balanced and each of its subgames is balanced as well.

One important property a game might satisfy is convexity. A game $(N, v)$ is called convex if for all $i \in N$ and all $S, T \subseteq N \backslash\{i\}$ with $S \subset T$,

$v(T \cup\{i\})-v(T) \geqslant v(S \cup\{i\})-v(S)$

Hence, for convex games, the marginal contribution of a player to any coalition is greater than his marginal contribution to a smaller coalition. A game is strictly convex if all inequalities are strict. We remark that convex games have non-empty cores.

\subsection{Monotonicity}

In this section, we introduce four monotonicity properties to capture two fair arguments for a general class of games. These monotonicity properties will be used further to investigate long term stability of the inventory pooling coalitions under changes.

Consider two games $(N, v)$ and $(N, w)$. We call the triple $(N, v, w)$ a pair of games if both games are totally balanced and $v(S) \geqslant w(S)$ for all $S \subseteq N$.

We call game $(N, v)$, which has larger values, the larger game and game $(N, w)$, which has smaller values, the smaller game. In a newsvendor environment, larger games represent collaboration in favorable conditions (e.g., high selling prices and low purchasing costs) whereas smaller games might result from a situation with restrictive conditions for possible coalitions (e.g., low selling prices and high purchasing costs).

The first fairness argument states that if the values of the coalitions in a game increase (decrease), it is possible that no player gets less (more) than before. Ichiishi (1990) introduces the following two monotonicity properties capturing this fairness argument.

- MP1: The pair of games $(N, v, w)$ has monotonicity property 1 (MP1) if for all $y \in \operatorname{Core}(w)$ there exists an $x \in \operatorname{Core}(v)$ such that $x \geqslant y$.

- MP2: The pair of games $(N, v, w)$ has monotonicity property 2 (MP2) if for all $x \in \operatorname{Core}(v)$ there exists a $y \in \operatorname{Core}(w)$ such that $y \leqslant x$.

If a pair of games has MP1 (MP2), then for all core elements of the smaller (larger) game, there is a core element of the larger (smaller) game such that no player gets less (more) than before. We remark that we want the new payoff vectors to be in the core, since those are stable. Moreover, we do not consider any specific bargaining process which will determine a mechanism to share the total expected profit and assume that any core element can be a feasible outcome for the grand coalition since all core elements are stable. Therefore, we check the entire core of game $w$ $(v)$ for MP1 (MP2).

Consider two games $(N, v)$ and $(N, w)$. We call the tuple $(N, v, w, i)$ a single deviation pair of games if both games are totally balanced and $i$ is a player in $N$ such that $v(S) \geqslant w(S)$ for all $S$ containing $i$ and $v(S)=w(S)$ for all $S$ not containing $i$. We call player $i$ the deviating player. Regarding to cooperative games associated with newsvendor situations, the deviating player represents the retailer, whose system parameters has changed. The second fairness argument states that if the value change of the coalitions is caused by one player, the other players should not get less than before. Besides, the deviating player should not get less either if its deviation improves these values. We introduce the following two monotonicity property to capture this fairness argument.

- MP3: The single deviation pair of games $(N, v, w, i)$ has monotonicity property 3 (MP3) if for all $y \in \operatorname{Core}(w)$ there exists an $x \in \operatorname{Core}(v)$ such that $x_{i} \geqslant y_{i}$ and $x_{j} \geqslant y_{j}$ for all $j \in N \backslash\{i\}$.

- MP4: The single deviation pair of games $(N, v, w, i)$ has monotonicity property 4 (MP4) if for all $x \in \operatorname{Core}(v)$ there exists a $y \in \operatorname{Core}(w)$ such that $y_{i} \leqslant x_{i}$ and $y_{j} \geqslant x_{j}$ for all $j \in N \backslash\{i\}$.

Similar as for MP1 and MP2, we check the entire core of game $w$ (v) for MP3 (MP4).

Note that monotonicity properties MP1 and MP3 differ from each other only because MP3 is defined for a special class of pairs of games, i.e., single deviation pair of games.

We use the following theorems to study the monotonicity of newsvendor games. The following theorem states that a pair of games with up to 3 players satisfies MP1 if the value of the grand coalition $N$ increases more than any other coalition $S \subset N$. The proof is presented in the online appendix.

Theorem 2. Let $(N, v, w)$ be a pair of games with $|N| \leqslant 3$. If $v(N)-w(N) \geqslant v(S)-w(S)$ for all $S \subseteq N$, then $(N, v, w)$ has MP1.

However, this result does not hold for pairs of games with arbitrary number of players. A counterexample can be found in Özen (2007).

The next theorem states that MP2 is naturally satisfied by pairs of games consisting of games with 2 players.

Theorem 3. Let $(N, v, w)$ be a pair of games such that $|N| \leqslant 2$. Then the pair of games $(N, v, w)$ has MP2.

Proof. The case with $|N|=1$ is trivial. Assume $N=\{1,2\}$. Consider another game $\left(N, v^{\prime}\right)$ such that

$v^{\prime}(\{1,2\})=v(\{1,2\}), v^{\prime}(\{1\})=w(\{1\}), \quad$ and $\quad v^{\prime}(\{2\})=w(\{2\})$.

Since $v^{\prime}(S)=w(S) \leqslant v(S)$ for all $S \subset N$ and $v^{\prime}(N)=v(N)$, Core $(v)$ $\subseteq \operatorname{Core}\left(v^{\prime}\right)$. Let $x$ be in the core of $(N, v)$. Then, $x \in \operatorname{Core}\left(v^{\prime}\right)$. Therefore, we can express $x$ as a convex combination of the extreme points of Core $\left(v^{\prime}\right)$. Let $\left(\lambda_{1}, \lambda_{2}\right)$ be such that $x=\lambda_{1}\left(v^{\prime}(\{1\}), v^{\prime}(\{1,2\})-v^{\prime}(\{1\})\right)$ $+\lambda_{2}\left(v^{\prime}(\{1,2\})-v(\{2\}), v^{\prime}(\{2\})\right)$ with $\lambda_{1} \in[0,1]$ and $\lambda_{2}=1-\lambda_{1}$. So $x=\lambda_{1}(w(\{1\}), v(\{1,2\})-w(\{1\}))+\lambda_{2}(v(\{1,2\})-w(\{2\}), w(\{2\}))$. Consider the division $y=\lambda_{1}(w(\{1\}), w(\{1,2\})-w(\{1\}))+\lambda_{2}(w(\{1,2\})$ $-w(\{2\}), w(\{2\}))$. Since $y$ is given by a convex combination of the extreme points of Core $(w), y \in \operatorname{Core}(w)$. Furthermore, since $(w(\{1\})$, $w(\{1,2\})-w(\{1\})) \leqslant(w(\{1\}), \quad v(\{1,2\})-w(\{1\}))$ and $(w(\{1,2\})-$ $w(\{2\}), w(\{2\})) \leqslant(v(\{1,2\})-w(\{2\}), w(\{2\}))$, we derive that $y \leqslant x$. This completes the proof.

However, this result does not extend to pairs of games with at least three players. Özen (2007) provides a counterexample.

The following two theorems give sufficient conditions for pairs of games with an arbitrary number of players to satisfy MP1 and MP2. They are due to Theorems 2.6 and 2.11 in Ichiishi (1990). Alternative proofs can be found in Özen (2007).

Theorem 4. Let $(N, v, w)$ be a pair of games. If $(N, v)$ is a convex game and $v(N)-w(N) \geqslant v(S)-w(S)$ for all $S \subseteq N$, then $(N, v, w)$ has MP1. 
Theorem 5. Let $(N, v, w)$ be a pair of games. If $(N, w)$ is a convex game, then $(N, v, w)$ has $M P 2$.

The following two theorems give sufficient conditions for MP3 and MP4, which are useful for case by case analysis.

Theorem 6. Let $(N, v, w, i)$ be a single deviation pair of games. If $v(N)-w(N) \geqslant v(S)-w(S)$ for all $S$ such that $i \in S$ and $S \subset N$, then $(N, v, w, i)$ has MP3.

Proof. Suppose that $v(N)-w(N) \geqslant v(S)-w(S)$ for all $S$ such that $i \in S$ and $S \subset N$. Recall that $v(S)=w(S)$ for all $S \subseteq N \backslash\{i\}$ since $(N, v, w, i)$ is a singleton deviating pair of games. Let $y \in \operatorname{Core}(w)$, and let $K=v(N)-w(N)$. Consider the payoff vector $x$ with $x_{j}=y_{j}$ for all $j \in N \backslash\{i\}$ and $x_{i}=y_{i}+K$. Then $\sum_{j \in S} x_{j}=\sum_{j \in S} y_{j} \geqslant w(S)=v(S)$ for all $S \subseteq N \backslash\{i\}, \sum_{j \in S} x_{j}=\sum_{j \in S} y_{j}+K \geqslant w(S)+K \geqslant v(S)$ for all $S \subset N$ with $i \in S$, and $\sum_{j \in N} x_{j}=\sum_{j \in N} y_{j}+K=w(N)+K=v(N)$. Hence, $x \in \operatorname{Core}(v)$. Furthermore, $x_{i} \geqslant y_{i}$ and $x_{j} \geqslant y_{j}$ for all $j \in N \backslash\{i\}$. This completes the proof.

Theorem 7. Let $(N, v, w, i)$ be a single deviation pair of games. If $v(N)-w(N) \leqslant v(S)-w(S)$ for all $S$ such that $i \in S$ and $S \subset N$, then $(N, v, w, i)$ has MP4.

Proof. Suppose that $v(N)-w(N) \leqslant v(S)-w(S)$ for all $S$ such that $i \in S$ and $S \subset N$. Recall that $v(S)=w(S)$ for all $S \subseteq N \backslash\{i\}$ since $(N, v, w, i)$ is a singleton deviating pair of games. Let $x \in \operatorname{Core}(v)$, and let $K=v(N)-w(N)$. Consider the payoff vector $y$ with $y_{j}=x_{j}$ for all $j \in N \backslash\{i\}$ and $y_{i}=x_{i}-K$. Then $\sum_{j \in S} y_{j}=\sum_{j \in S} x_{j} \geqslant v(S)=w(S)$ for all $S \subseteq N \backslash\{i\}, \sum_{j \in S} y_{j}=\sum_{j \in S} x_{j}-K \geqslant v(S)-K \geqslant w(S)$ for all $S \subset N$ with $i \in S$, and $\sum_{j \in N} y_{j}=\sum_{j \in N} x_{j}-K=v(N)-K=w(N)$. Hence, $y \in \operatorname{Core}(w)$. Furthermore, $y_{i} \leqslant x_{i}$ and $y_{j} \geqslant x_{j}$ for all $j \in N \backslash\{i\}$. This completes the proof.

Table 1 summarizes the sufficient conditions presented in Theorems $2-7$. Note that the conditions are valid for the class of totally balanced games including the newsvendor games.

In this research, we use the monotonicity properties as an instrument to determine the long term stability for cooperation in a newsvendor setting which is subject to changes in the environment (e.g., changing dedicated stock levels, prices and cost parameters). In our situation, determining a new core allocation, which does not discriminate against any of the retailers, is favorable for the retailers. Even though it might not be possible in all situations, studying these monotonicity properties is important to develop an understanding about what the retailers can or cannot expect from

Table 1

Sufficient conditions for MP1, MP2, MP3 and MP4.

\begin{tabular}{|c|c|}
\hline MP1 & \\
\hline$|N| \leqslant 3$ (Theorem 2) & $v(N)-w(N) \geqslant v(S)-w(S)$ for all $S \subseteq N$ \\
\hline $\begin{array}{l}\text { Arbitrary number of players } \\
\text { (Theorem } 4 \text { ) }\end{array}$ & $\begin{array}{l}v(N)-w(N) \geqslant v(S)-w(S) \text { for all } S \subseteq N \text { and } \\
\quad v \text { is convex }\end{array}$ \\
\hline MP2 & \\
\hline$|N| \leqslant 2$ (Theorem 3$)$ & No condition required \\
\hline $\begin{array}{l}\text { Arbitrary number of players } \\
\text { (Theorem } 5 \text { ) }\end{array}$ & $w$ is convex \\
\hline MP3 ( $i$ is the deviating player) & \\
\hline $\begin{array}{l}\text { Arbitrary number of players } \\
\text { (Theorem 6) }\end{array}$ & $\begin{array}{l}v(N)-w(N) \geqslant v(S)-w(S) \text { for all } S \subseteq N \\
\quad \text { with } i \in S\end{array}$ \\
\hline MP4 ( $i$ is the deviating player) & \\
\hline $\begin{array}{l}\text { Arbitrary number of players } \\
\text { (Theorem 7) }\end{array}$ & $\begin{array}{l}v(N)-w(N) \leqslant v(S)-w(S) \text { for all } S \subseteq N \\
\quad \text { with } i \in S\end{array}$ \\
\hline
\end{tabular}

the cooperation to secure their further participation to the cooperation and coordinated decision making. In the remainder of the paper, we study stability and monotonicity of newsvendor games, mainly focusing on MP1 and MP2. We identify several classes of newsvendor games satisfying these properties with the help of the sufficient conditions derived in this section. Although we do not study MP3 and MP4 extensively in the rest of the paper, the sufficient conditions derived here are easy to check and can be used in case by case analysis of newsvendor situations.

\section{Model and analysis}

\subsection{Model}

In this section, we introduce newsvendor situations with dedicated stock and define the associated cooperative games. Then, we show that these games have non-empty cores. Recall that missing proofs of theorems and lemmas can be found in the online appendix.

Consider a set $N=\{1, \ldots, n\}$ of retailers selling the same product. Each retailer $i \in N$ experiences a stochastic demand $X_{i}$ with finite expectation and has to give an order to the same supplier before the demand realization. ${ }^{1}$ Moreover, each retailer $i \in N$ has a unit $\operatorname{cost} c_{i}$, which includes purchasing and transportation costs, a selling price $p_{i}$ and a penalty cost $g_{i}$. Throughout the study, we assume that $p_{i}, c_{i}$ and $g_{i}$ are positive, and $p_{i} \geqslant c_{i}$ for all $i \in N$. Besides, different from the standard newsvendor model, each retailer would like to satisfy his own demand up to a certain amount for sure. This amount is denoted by $\varepsilon_{i}$ for retailer $i \in N$. If realized demand is less than this amount, then the whole demand is critical and the retailer would like to satisfy it all. We call $\varepsilon_{i}$ the dedicated stock level of retailer $i$. In single newsvendor setting, the dedicated stock level can be seen as the minimum order quantity for a retailer to meet a certain service level. A tuple $\left(N,\left(X_{i}\right)_{i \in N},\left(c_{i}\right)_{i \in N},\left(p_{i}\right)_{i \in N},\left(g_{i}\right)_{i \in N},\left(\varepsilon_{i}\right)_{i \in N}\right)$ with $N, X_{i}, c_{i}$,$p_{i}, g_{i}$ and $\varepsilon_{i}$ as above is called a newsvendor situation with dedicated stock. For convenience, we will, in the rest of the paper, refer to newsvendor situations with dedicated stock simply as newsvendor situations. We remark that in this model the retailers concerns about losing a customer demand is reflected by two parameters; penalty cost $g_{i}$ and dedicated stock level $\varepsilon_{i}$. Hence, this model is rich enough to cover two specific settings; one with $g_{i}=0$ for all $i \in N$, and one with $\varepsilon_{i}=0$ for all $i \in N$. Moreover, if the retailers join a coalition, the dedicated stock levels also reflect the retailers' concerns about the allocation of the joint order quantity after demand realization.

Consider a newsvendor situation and a collection of retailers $S$. If these retailers come together and form coalition $S$, they might increase their total profit by giving a joint order and splitting it after demand realization. Such a joint order $q^{S}$ should not create any infeasibility for coalition $S$ with respect to the dedicated stock levels of the retailers in $S$, i.e., $q^{S} \geqslant \sum_{i \in S} \varepsilon_{i}$. The collection of possible orders of coalition $S$ is given by

$Q^{S}:=\left\{q \in \mathbb{R} \mid q \geqslant \sum_{i \in S} \varepsilon_{i}\right\}$.

Let $\left(x_{i}\right)_{i \in S}$ be a realization of demand vector $X^{S}=\left(X_{i}\right)_{i \in S}$. For notational convenience, we will denote this realization as the vector $x^{S} \in \mathbb{R}^{N}$ where $x_{i}^{S}=0$ for all $i \in N \backslash S$ and $x_{i}^{S}=x_{i}$ for all $i \in S$. Suppose coalition $S$ has ordered $q^{S} \in Q^{S}$ and demands are realized as $x^{S}$. Then the retailers in $S$ can allocate the joint order among themselves to satisfy the demands. An allocation of $q^{S}$ is a vector $a^{S} \in \mathbb{R}_{+}^{N}$ with

\footnotetext{
${ }^{1}$ In most practical applications $X_{i}$ can not take negative values. However, in this work we allow $X_{i}$ to take negative values with very low probabilities to cover some well known distributions (e.g., normal distribution). Besides, negative demand can be interpreted as returns from customers.
} 
$\mathrm{a}_{i}^{S}=0 \quad$ if $i \in N \backslash S$,

$\sum_{i \in S} \mathrm{a}_{i}^{S}=q^{S}$

$\mathrm{a}_{i}^{S} \geqslant \min \left\{x_{i}, \varepsilon_{i}\right\} \quad$ for all $i \in S$.

Here, $\mathrm{a}_{i}^{S}$ denotes the amount of product that will be sent from the supplier to retailer $i$. The set of all possible allocations for coalition $S$ of an order vector $q^{S} \in Q^{S}$ is denoted by $M^{S}\left(q^{S}, x^{S}\right)$. Note that it is not allowed to ship goods to retailers that are not in coalition $S$. Moreover, an allocation should satisfy $\mathrm{a}_{i}^{S} \geqslant \min \left\{x_{i}, \varepsilon_{i}\right\}$ for each retailer $i \in S$ since each retailer wants to utilize his dedicated stock when the demand is high. We remark that, since the actual allocation of the joint order takes place after demand realization, retailer $i$ can possibly get less than $\varepsilon_{i}$ if $x_{i} \leqslant \varepsilon_{i}$ to improve the profit of the coalition. Finally, we assume that at the end of the period all ordered units should be transferred to the retailers. This assumption can be interpreted as the opportunity to salvage the leftover products is only available or more beneficial at the retailers. ${ }^{2}$

For a fixed order quantity $q^{S} \in Q^{S}$, demand realization $x^{S}$ of $X^{S}$, and allocation vector $\mathrm{a}^{S} \in M^{S}\left(q^{S}, x^{S}\right)$ the profit of coalition $S$ can be expressed as

$P^{S}\left(\mathrm{a}^{S}, q^{S}, x^{S}\right)=-\sum_{i \in S} \mathrm{a}_{i}^{S} c_{i}+\sum_{i \in S}\left(p_{i}+g_{i}\right) \min \left\{\mathrm{a}_{i}^{S}, x_{i}^{S}\right\}-\sum_{i \in S} g_{i} x_{i}^{S}$.

Note that in the profit function, we do not consider any extra cost for the allocation of the joint order. This is natural for the cases, where the individual orders of the retailers follow the same route up to a point. So, if the demand realization occurs before the orders reach this point, the allocation of the joint order of a coalition can take place without any additional cost.

The following lemma shows that an optimal allocation exists for a given coalition, order quantity and demand realization.

Lemma 1. Let $\left(N,\left(X_{i}\right)_{i \in N},\left(c_{i}\right)_{i \in N},\left(p_{i}\right)_{i \in N},\left(g_{i}\right)_{i \in N},\left(\varepsilon_{i}\right)_{i \in N}\right)$ be a newsvendor situation, let $S \subseteq N$, let $q^{S} \in Q^{S}$, and let $x^{S}$ be a demand realization vector. There exists an allocation $a^{S, *} \in M^{S}\left(q^{S}, x^{S}\right)$ that maximizes the profit $P^{S}\left(\cdot, q^{S}, x^{S}\right)$ of coalition $S$.

From now on, we refer to $P^{S}\left(a^{S, *}, q^{S}, x^{S}\right)$ as $r^{S}\left(q^{S}, x^{S}\right)$. The expected profit function of coalition $S$ is defined by

$\pi^{S}\left(q^{S}\right)=E_{X^{S}}\left[r^{S}\left(q^{S}, \cdot\right)\right]$.

The following theorem shows that for any coalition an optimal order quantity, which maximizes expected total profit of this coalition, exists.

Theorem 8. Let $\left(N,\left(X_{i}\right)_{i \in N},\left(c_{i}\right)_{i \in N},\left(p_{i}\right)_{i \in N},\left(g_{i}\right)_{i \in N},\left(\varepsilon_{i}\right)_{i \in N}\right)$ be a newsvendor situation and let $S \subseteq N$. There exists an order quantity $q^{S, *}$ that maximizes the expected profit function $\pi^{S}(\cdot)$ of coalition $S$.

The determination of an optimal order quantity requires solving a two stage stochastic program, where in the first stage the order quantity is determined and in the second stage, given the order quantity and demand realizations, an allocation decision is made. There exists a solution algorithm, which utilizes backward induction process.

Let $\Gamma$ be a newsvendor situation. The associated cooperative game $\left(N, v^{\Gamma}\right)$ is defined by

$$
v^{\Gamma}(S)=\max _{q^{S} \in Q^{S}} \pi^{S}\left(q^{S}\right) \text { for all } S \subseteq N .
$$

The value of a coalition is given by the optimal value of the profit maximization problem of the coalition. Recall that the optimal or-

\footnotetext{
${ }^{2}$ We remark that, in our model, we do not include any salvage value for the retailers. However, we can incorporate the salvage values $v_{i}$ by defining new selling prices and costs as $\bar{p}_{i}=p_{i}-v_{i}$ and $\bar{c}_{i}=c_{i}-v_{i}$ for all $i \in N$.
}

der quantity that maximizes the expected profit function of a coalition $S \subseteq N$ is denoted by $q^{S, *}$.

The following theorem shows that cooperative games associated with newsvendor situations are totally balanced, and hence, they have non-empty cores.

Theorem 9. Let $\left(N,\left(X_{i}\right)_{i \in N},\left(c_{i}\right)_{i \in N},\left(p_{i}\right)_{i \in N},\left(g_{i}\right)_{i \in N},\left(\varepsilon_{i}\right)_{i \in N}\right)$ be a newsvendor situation. The associated cooperative game is totally balanced and has a non-empty core.

Chen and Zhang (2009) presented a unified approach to identify core elements of inventory centralization games using duality of two stage stochastic programs. Referring to an earlier version of this manuscript, Chen and Zhang (2009) also described that their approach includes the case covered here.

\subsection{Monotonicity of newsvendor games}

In the previous section, we showed that every cooperative game associated with a newsvendor situation has a nonempty core, which provides a stable profit division for the grand coalition under fixed dedicated stock levels of the retailers. Another important issue to consider is how the payoffs of the retailers are affected by a change in the system parameters, e.g., dedicated stock levels, purchasing and selling prices, and penalty costs of the retailers.

To investigate this situation, we use the following proposition, which shows how the value of a coalition is affected by a change in the system parameters of its retailers. We skip the obvious proof.

Proposition 1. Let $\Gamma^{1}=\left(N,\left(X_{i}\right)_{i \in N},\left(c_{i}^{1}\right)_{i \in N},\left(p_{i}^{1}\right)_{i \in N},\left(g_{i}^{1}\right)_{i \in N},\left(\varepsilon_{i}^{1}\right)_{i \in N}\right)$ and $\left.\Gamma^{2}=\left(N,\left(X_{i}\right)_{i \in N}, c_{i}^{2}\right)_{i \in N},\left(p_{i}^{2}\right)_{i \in N},\left(g_{i}^{2}\right)_{i \in N},\left(\varepsilon_{i}^{2}\right)_{i \in N}\right)$ be two newsvendor situations such that $\varepsilon_{i}^{1} \leqslant \varepsilon_{i}^{2}, p_{i}^{1} \geqslant p_{i}^{2}, c_{i}^{1} \leqslant c_{i}^{2}$ and $g_{i}^{1} \leqslant g_{i}^{2}$ for all $i \in N$, and there is a $T \subseteq N$ with $\varepsilon_{i}^{1}<\varepsilon_{i}^{2}$ and $\backslash$ or $p_{i}^{1}>p_{i}^{2}$ and $\backslash$ or $c_{i}^{1}<c_{i}^{2}$ and $\backslash$ or $g_{i}^{1}<g_{i}^{2}$ for all $i \in T$, and $\varepsilon_{i}^{1}=\varepsilon_{i}^{2}, p_{i}^{1}=p_{i}^{2}, c_{i}^{1}=c_{i}^{2}$ and $g_{i}^{1}=g_{i}^{2}$ for all $i \in N \backslash T$. Then the following relation holds for their associated games $\left(N, v^{\Gamma^{1}}\right)$ and $\left(N, v^{\Gamma^{2}}\right)$ :

$$
\begin{aligned}
& v^{\Gamma^{1}}(S) \geqslant v^{\Gamma^{2}}(S) \quad \text { for all } S \text { with } S \bigcap T \neq \emptyset, \\
& v^{\Gamma^{1}}(S)=v^{\Gamma^{2}}(S) \quad \text { for all } S \text { with } S \bigcap T=\emptyset .
\end{aligned}
$$

In words, the value of a coalition increases if a group of retailers in the coalition decreases their dedicated stock levels. Moreover, the value is increasing with decreasing purchasing and penalty costs, and increasing selling prices. This result is quite intuitive, since the possibilities of what a coalition can do are enlarged with lower dedicated stock levels of the retailers, i.e., the solution space of the profit maximization problem is enlarged, and the costs and revenues are more favorable in situation $\Gamma^{1}$. Decreasing dedicated stock levels, purchasing costs and penalty costs as well as increasing selling prices will be called changes in a positive direction whereas reverse adjustments will be called changes in a negative direction.

In newsvendor situations, one might be interested in two types of changes in the system parameters (e.g., dedicated stock levels and selling prices). In the first one, all retailers' parameters are weakly changed simultaneously in either a positive or a negative direction. This might lead to a change in the value of the grand coalition as well as in the values of some other coalitions as stated in Proposition 1. Since it is hard to distinguish the effect of retailers on the change of these values, the simplest fairness argument states that none of the retailers should get less (more) than before if the values of the coalitions increase (decrease). In other words, the payoffs of the retailers should be affected in the same direction as the game changes due to the change in the system parameters. Note that we want all profit divisions (before and after a change in dedicated stock levels) to be stable since we consider it as a 
necessity for a possible cooperation. We use MP1 and MP2 to analyze this type of changes. We remark that if $|N|=2,\left(N, v^{\Gamma^{1}}, v^{\Gamma^{2}}\right)$, which is defined in Proposition 1, has MP2 following from Proposition 1 and Theorem 3.

In the latter type of change, only a single retailer's parameter is changed, which might lead to a change in the value of the grand coalition as well as in the values of some other coalitions all involving this player. Since it is known that the changes are caused by this specific retailer, other retailers do not want to be harmed by this change. A fairness argument to follow would be that none of these non-changing retailers should get less than what they got before. MP3 and MP4 capture this fairness argument and the sufficient conditions in Theorems 6 and 7 are useful to make a case by case analysis of newsvendor situations.

\subsubsection{Cost parameters}

In this part of the study, we study the changes in system cost parameters, i.e., $p_{i}, c_{i}$ and $g_{i}$. From Proposition 1, we know how the value of a coalition changes with a shift in the system cost parameters. However, knowing the direction (sign) of the change is not sufficient to ensure the games to satisfy the monotonicity properties. From the sufficient conditions presented in the preliminaries, we have seen that magnitudes of changes in the values of coalitions play a critical role. In a newsvendor environment, the magnitude of the change in the profit of a coalition depends on the parameters of each retailer (e.g., dedicated stock levels, selling prices, demand distributions) in the coalition and, hence, can differ significantly from one coalition to another. Therefore, it is very much parameter dependent whether a pair or a single deviation pair of newsvendor games satisfies the monotonicity properties or not. In the rest of the section, we assume symmetric retailers in their selling prices and costs, i.e., $p_{i}=p, c_{i}=c$ and $g_{i}=g$ for all $i \in N$. This is a realistic assumption especially for the situations where the retailers sell the same product in similar markets. In these situations, the customers' perception (or valuation) of the product does not show many differences in retailers' markets and the retailers do not perform any additional value added activities on the products. We denote a cost symmetric newsvendor situation (CSNS) by $\Pi^{C S N S}=\left(N,\left(X_{i}\right)_{i \in N}, C, p, g,\left(\varepsilon_{i}\right)_{i \in N}\right)$. Let $f_{S}$ and $F_{S}$ denote the probability density function and probability distribution function of $X_{S}=\sum_{i \in S} X_{i}$, respectively. In a CSNS, there is no difference in satisfying demands for different retailers in terms of total profit of a coalition because of common purchasing cost, selling price and penalty cost, i.e., $\sum_{i \in S} \min \left\{a_{i}^{S}, x_{i}^{S}\right\}=\min \left\{q^{S}, \sum_{i \in S} x_{i}^{S}\right\}$ for all $S \subseteq N$. Therefore, the profit function of coalition $S$ can be written as follows

$\pi^{S}\left(q^{S}\right)=-c * q^{S}+p \int_{0}^{q^{S}} \bar{F}_{S}(x) d x-p \int_{-\infty}^{0} F_{S}(x) d x-g \int_{q^{S}}^{\infty} \bar{F}_{S}(x) d x$,

where $\overline{F_{S}}=1-F_{S}$. In inventory literature, it is known that $\pi^{S}(q)$ (the profit function of newsvendor problem without any dedicated stock) is a concave function and the optimum $\bar{q}^{S}$ maximizing this function satisfies $F_{S}\left(\bar{q}^{S}\right)=1-c /(p+g)$. Since $\pi^{S}(q)$ is concave, it follows immediately that the optimal order quantity of coalition $S$ is the maximum of the optimal order quantity of the newsvendor problem without any dedicated stock and the sum of the dedicated stock levels of the retailers in $S$, i.e., $q^{S}=\max \left\{\bar{q}^{S}, \sum_{i \in S} \varepsilon_{i}\right\}$. Let $\left(N, v^{\Pi^{\mathrm{CSNS}}}\right)$ be the associated newsvendor game. Then, the profit of coalition $S$ is given by

$v^{\Pi^{\mathrm{SNS} S}}(S)=-c * q^{S}+p \int_{0}^{q^{S}} \bar{F}_{S}(x) d x-p \int_{-\infty}^{0} F_{S}(x) d x-g \int_{q^{S}}^{\infty} \bar{F}_{S}(x) d x$.

Our first result is for newsvendor games with two and three retailers.
Theorem 10. Let $\Pi^{1}=\left(N,\left(X_{i}\right)_{i \in N}, c^{1}, p^{1}, g,\left(\varepsilon_{i}\right)_{i \in N}\right) \quad$ and $\Pi^{2}=\left(N,\left(X_{i}\right)_{i \in N}, c^{2}, p^{2}, g,\left(\varepsilon_{i}\right)_{i \in N}\right)$ with $|N| \leqslant 3, X_{i} \in[0, \infty)$ for all $i \in N$, $p^{1} \geqslant p^{2}$ and $c^{1} \leqslant c^{2}$ be two CSNSs. Let $\left(N, v^{\Pi^{1}}\right)$ and $\left(N, v^{\Pi^{2}}\right)$ be the newsvendor games associated with $\Pi^{1}$ and $\Pi^{2}$, respectively. Then, pair of newsvendor games $\left(N, v^{\Pi^{1}}, v^{\Pi^{2}}\right)$ has MP1.

Proof. From Theorem 2, it is enough to show that $v^{\Pi^{1}}(N)-v^{\Pi^{2}}(N) \geqslant v^{\Pi^{1}}(S)-v^{\Pi^{2}}(S)$ for all $S \subseteq N$. Consider coalition $S \subseteq N$. Since $X_{i} \in[0, \infty)$, we know that

$F_{N}(y) \leqslant F_{S}(y)$ for all $y \in \mathbb{R}$.

Define the following generic profit function

$d_{S}(p, c)=-c * q^{S}(p, c)+p \int_{0}^{q^{S}(p, c)} \bar{F}_{S}(x) d x-g \int_{q^{S}(p, c)}^{\infty} \bar{F}_{S}(x) d x$,

where $q^{S}(p, c)=\max \left\{\bar{q}^{S}, \sum_{i \in S} \varepsilon_{i}\right\}$ such that $F_{S}\left(\bar{q}^{S}\right)=1-c /(p+g)$. Then,

$v^{\Pi^{1}}(S)=d_{S}\left(p^{1}, c^{1}\right)$.

Moreover,

$v^{\Pi^{1}}(S)-v^{\Pi^{2}}(S)=\int_{p^{2}}^{p^{1}} \frac{\partial d_{S}\left(p, c^{2}\right)}{\partial p}-\int_{c^{1}}^{c^{2}} \frac{\partial d_{S}\left(p^{1}, c\right)}{\partial c}$.

From the envelope theorem, it follows that

$\frac{\partial d_{S}\left(p, c^{2}\right)}{\partial p}=\int_{0}^{q^{S}\left(p, c^{2}\right)} \bar{F}_{S}(x) d x \quad$ and $\quad \frac{\partial d_{S}\left(p^{1}, c\right)}{\partial c}=-q^{S}\left(p^{1}, c\right)$.

Then showing that

$\frac{\partial d_{N}\left(p, c^{2}\right)}{\partial p} \geqslant \frac{\partial d_{S}\left(p, c^{2}\right)}{\partial p}$ and $-\frac{\partial d_{N}\left(p^{1}, c\right)}{\partial c} \geqslant-\frac{\partial d_{S}\left(p^{1}, c\right)}{\partial c}$

is enough to prove the theorem. Since $\bar{F}_{N}(x) \geqslant \bar{F}_{S}(x)$ for every $x \in[0, \infty)$ (from (1)) and $\sum_{i \in N} \varepsilon_{i} \geqslant \sum_{i \in S} \varepsilon_{i}$, we know that $q^{N}\left(p, c^{2}\right) \geqslant q^{S}\left(p, c^{2}\right)$ and $q^{N}\left(p^{1}, c\right) \geqslant q^{S}\left(p^{1}, c\right)$. Therefore, we conclude that

$\frac{\partial d_{N}\left(p, c^{2}\right)}{\partial p} \geqslant \frac{\partial d_{S}\left(p, c^{2}\right)}{\partial p}$ and $-\frac{\partial d_{N}\left(p^{1}, c\right)}{\partial c} \geqslant-\frac{\partial d_{S}\left(p^{1}, c\right)}{\partial c}$.

We remark that this result holds under any demand distribution with nonnegative demand and it covers any correlation structure. However, a similar result does not hold in general when penalty costs are in concern and demands are negatively correlated as illustrated by the following example.

Example 1. Consider two CSNS $\left.\Pi^{1}=\left(N,\left(X_{i}\right)_{i \in N}, c, p, g^{1}, \varepsilon_{i}\right)_{i \in N}\right)$, and $\Pi^{2}=\left(N,\left(X_{i}\right)_{i \in N}, c, p, g^{2},\left(\varepsilon_{i}\right)_{i \in N}\right)$ such that $N=\{1,2\}, c=1, p=2, g^{1}<g^{2}$. Let $X_{1}$ be normally distributed with mean $\mu>0$, and let $X_{2}=a \mu-X_{1}$ with $a>1$. In other words, $X_{1}$ and $X_{2}$ are negatively correlated. Therefore, $X_{N}$ is deterministic demand with realization $a \mu$.

It is straightforward to validate that $v^{\Pi^{1}}(N)=v^{\Pi^{2}}(N)=(p-c)$ $a \mu$, and it follows from Proposition 1 that $v^{\Pi^{1}}(\{i\})>v^{\Pi^{2}}(\{i\})$ for all $i \in N$. Let $x \in \operatorname{Core}\left(v^{\Pi^{1}}\right)$. Since $x_{1}+x_{2}=v^{\Pi^{1}}(N)$ and $x_{1} \geqslant v^{\Pi^{1}}(\{1\})$, we derive that $x_{2} \leqslant v^{\Pi^{1}}(N)-v^{\Pi^{1}}(\{1\})$. Consider the payoff vector $y=\left(v^{\Pi^{2}}(\{1\}), v^{\Pi^{2}}(N)-v^{\Pi^{2}}(\{1\})\right) \in \operatorname{Core}\left(v^{\Pi^{2}}\right)$. Then there is no $x \in \operatorname{Core}\left(v^{\Pi^{1}}\right)$ such that $x_{2} \geqslant y_{2}$, since $x_{2} \leqslant v^{\Pi^{1}}(N)-v^{\Pi^{1}}(\{1\})<$ $v^{\Pi^{2}}(N)-v^{\Pi^{2}}(\{1\})$ for all $x \in \operatorname{Core}\left(v^{\Pi^{1}}\right)$. So pair of games $\left(N, v^{\Pi^{1}}, v^{\Pi^{2}}\right)$ does not have MP1.

Before presenting our second set of results, we introduce more notation and we turn our focus to the situations with independent normally distributed demand. In many practical situations, demand can be modeled as normal distribution and these distributions will 
be independent if the retailers' markets are separate enough, e.g., the variability in demand results from the local factors. Another realistic scenario is that the retailers commonly use point forecasting methods, the error of which follows normal distribution. As the error results from independent processes, these cases can be realistically modeled as independent normally distributed demand.

Consider a CSNS $\Pi=\left(N,\left(X_{i}\right)_{i \in N}, C, p, g,\left(\varepsilon_{i}\right)_{i \in N}\right)$ with $X_{i}$ having independent normal distribution $N\left(\mu_{i}, \sigma_{i}\right)$. Furthermore, assume that $F_{S}\left(\sum_{i \in S} \varepsilon_{i}\right) \leqslant 1-c /(p+g)$ for all $S \subseteq N$. This assumption indicates that the dedicated stock levels are not imposing any coalition to order more than the optimal order quantity without any restrictions. However, the dedicated stock levels are still important because they restrict the allocations after demand realization. Consider coalition $S$. Since optimal order quantity for coalition $S$ satisfies $F_{S}(\bar{q})=1-c /(p+g)$ we know that $\bar{q} \geqslant \sum_{i \in S} \varepsilon_{i}$ and hence $q^{S}=\bar{q}$. Since $X_{i}^{\prime}$ s are independent and normally distributed, $X_{S}$ is normally distributed with parameters $\mu_{S}=\sum_{i \in S} \mu_{i}$ and $\sigma_{S}^{2}=\sum_{i \in S} \sigma^{2}$. Therefore, $\bar{q}=\mu_{S}+k_{1-c /(p+g)} \sigma_{S}$, where $k_{1-c /(p+g)}$ is the unique number such that the standard normal cumulative distribution function $\Theta$ satisfies $\Theta\left(k_{1-c /(p+g)}\right)=1-c /(p+g)$. Let $\left(N, v^{\Pi}\right)$ be the associated newsvendor game. Then, the profit of coalition $S$ is given by

$v^{\Pi}(S)=-c q^{S}+p \mu_{S}-(p+g) \sigma_{S} G\left(k_{1-c /(p+g)}\right)$,

where $G(u)=\int_{u}^{\infty}(1-\Theta(x)) d x$. We remark that $\mu_{S}+k_{1-c /(p+g)} \sigma_{S}$ and $\mu_{S}-\sigma_{S} G\left(k_{1-c /(p+g)}\right)$ are the optimal order quantity and expected sales under optimal order quantity for coalition $S$, respectively. We expect them to be positive in a meaningful newsvendor situation.

The following lemma follows from Theorem 2 of Özen et al. (2011).

Lemma 2. Let $\Pi=\left(N,\left(X_{i}\right)_{i \in N}, c, p, g,\left(\varepsilon_{i}\right)_{i \in N}\right)$ with $X_{i}$ having independent normal distribution such that $F_{S}\left(\sum_{i \in S} \varepsilon_{i}\right) \leqslant 1-c /(p+g)$ for all $S \subseteq N$ be a CSNS. The associated newsvendor game $\left(N, v^{I}\right)$ is convex.

The next theorem considers newsvendor situations with an arbitrary number of players.

Theorem 11. Let $\Pi^{1}=\left(N,\left(X_{i}\right)_{i \in N}, c^{1}, p^{1}, g^{1},\left(\varepsilon_{i}\right)_{i \in N}\right)$ and $\Pi^{2}=\left(N,\left(X_{i}\right)_{i \in N}\right.$, $\left.c^{2}, p^{2}, g^{2},\left(\varepsilon_{i}\right)_{i \in N}\right)$ with $X_{i}$ having independent normal distribution such that $\mu_{i}-\sigma_{i} G\left(k_{1-c^{2} /\left(p^{2}+g^{2}\right)}\right) \geqslant 0$ and $\mu_{i}+k_{1-c^{2} /\left(p^{2}+g^{2}\right)} \sigma_{i} \geqslant 0$ for all $i \in N, F_{S}\left(\sum_{i \in S} \varepsilon_{i}\right) \leqslant 1-c^{2} /\left(p^{2}+g^{2}\right) \quad$ and $\quad F_{S}\left(\sum_{i \in S} \varepsilon_{i}\right) \leqslant 1-c^{1} /\left(p^{1}\right.$ $\left.+g^{1}\right)$ for all $S \subseteq N, p^{1} \geqslant p^{2}, c^{1} \leqslant c^{2}$, and $g^{1} \leqslant g^{2}$ be two CSNSs. Let $\left(N, v^{\Pi^{1}}\right)$ and $\left(N, v^{\Pi^{2}}\right)$ be the newsvendor games associated with $\Pi^{1}$ and $\Pi^{2}$, respectively. Then, pair of newsvendor games $\left(N, v^{\Pi^{1}}, v^{\Pi^{2}}\right)$ has MP1 and MP2.

Proof. From Lemma 2 and Theorem 5, it follows that $\left(N, v^{\Pi^{1}}, v^{\Pi^{2}}\right)$ has MP2.

From Theorem 4 and Lemma 2, it is enough to show that $v^{\Pi^{1}}(N)-v^{\Pi^{2}}(N) \geqslant v^{\Pi^{1}}(S)-v^{\Pi^{2}}(S)$ for all $S \subseteq N$. We use a similar technique as in the proof of Theorem 10.

Consider coalition $S \subseteq N$. Define the following generic profit function

$\left.d_{S}(p, c, g)\right)=-c q^{S}(p, c, g)+p \mu_{S}-(p+g) \sigma_{S} G\left(k_{1-c /(p+g)}\right)$,

where $q^{S}(p, c, g)=\mu_{S}+k_{1-c /(p+g)} \sigma_{S}$. Therefore, $F_{S}\left(q^{S}(p)\right)=1-c /(p+g)$. Then,

$v^{\Pi^{1}}(S)=d_{S}\left(p^{1}, c^{1}, g^{1}\right)$.

Moreover,

$v^{\Pi^{1}}(S)-v^{\Pi^{2}}(S)=\int_{p^{2}}^{p^{1}} \frac{\partial d_{S}\left(p, c^{2}, g^{2}\right)}{\partial p}-\int_{c^{1}}^{c^{2}} \frac{\partial d_{S}\left(p^{1}, c, g^{2}\right)}{\partial c}-\int_{g^{1}}^{g^{2}} \frac{\partial d_{S}\left(p^{1}, c^{1}, g\right)}{\partial g}$
From the envelope theorem, it follows that

$\frac{\partial d_{S}\left(p, c^{2}, g^{2}\right)}{\partial p}=\mu_{S}-\sigma_{S} G\left(k_{1-c^{2} /\left(p+g^{2}\right)}\right), \frac{\partial d_{S}\left(p^{1}, c, g^{2}\right)}{\partial c}=-q^{S}\left(p^{1}, c, g^{2}\right)$

and

$\frac{\partial d_{S}\left(p^{1}, c^{1}, g\right)}{\partial g}=-\sigma_{S} G\left(k_{1-c^{1} /\left(p^{1}+g\right)}\right)$.

To complete the proof, we will show that

$$
\begin{aligned}
& \frac{\partial d_{N}\left(p, c^{2}, g^{2}\right)}{\partial p} \geqslant \frac{\partial d_{S}\left(p, c^{2}, g^{2}\right)}{\partial p} \quad \text { for all } p \in\left[p^{2}, p^{1}\right], \\
& -\frac{\partial d_{N}\left(p^{1}, c, g^{2}\right)}{\partial c} \geqslant-\frac{\partial d_{s}\left(p^{1}, c, g^{2}\right)}{\partial c} \quad \text { for all } c \in\left[c^{1}, c^{2}\right], \quad \text { and } \\
& -\frac{\partial d_{N}\left(p^{1}, c^{1}, g\right)}{\partial g} \geqslant-\frac{\partial d_{S}\left(p^{1}, c^{1}, g\right)}{\partial g} \quad \text { for all } g \in\left[g^{1}, g^{2}\right] .
\end{aligned}
$$

$\frac{\partial d_{N}\left(p, c^{2}, g^{2}\right)}{\partial p}-\frac{\partial d_{S}\left(p, c^{2}, g^{2}\right)}{\partial p}=\mu_{N}-\sigma_{N} G\left(k_{1-c^{2} /\left(p+g^{2}\right)}\right)-\mu_{S}$

$$
\begin{aligned}
& +\sigma_{S} G\left(k_{1-c^{2} /\left(p+g^{2}\right)}\right) \\
= & \mu_{N \backslash S}-\left(\sigma_{N}-\sigma_{S}\right) G\left(k_{1-c^{2} /\left(p+g^{2}\right)}\right) \\
\geqslant & \mu_{N \backslash S}-\sigma_{N \backslash S} G\left(k_{1-c^{2} /\left(p+g^{2}\right)}\right) \\
\geqslant & \sum_{i \in N \backslash S}\left(\mu_{i}-\sigma_{i} G\left(k_{1-c^{2} /\left(p+g^{2}\right)}\right)\right) \\
\geqslant & 0 \text { for all } p \in\left[p^{2}, p^{1}\right] .
\end{aligned}
$$

The first and second inequality hold because

$\sqrt{a^{2}+b^{2}} \leqslant a+b$ for all $a, b \in \mathbb{R}^{+}$.

The last inequality follows from the assumption that $\mu_{i}-\sigma_{i} G\left(k_{1-c^{2} /\left(p^{2}+g^{2}\right)}\right) \geqslant 0$ for all $i \in N$ and because $G(u)$ is a decreasing function.

First, suppose that $\Theta^{-1}\left(1-c /\left(p^{1}+g^{2}\right)\right) \geqslant 0$. Then

$$
\begin{aligned}
-\frac{\partial d_{N}\left(p^{1}, c, g^{2}\right)}{\partial c}+\frac{\partial d_{S}\left(p^{1}, c, g^{2}\right)}{\partial c}= & \mu_{N}+k_{1-c /\left(p^{1}+g^{2}\right)} \sigma_{N}-\mu_{S} \\
& -k_{1-c /\left(p^{1}+g^{2}\right)} \sigma_{S} \\
= & \mu_{N \backslash S}+k_{1-c /\left(p^{1}+g^{2}\right)}\left(\sigma_{N}-\sigma_{S}\right) \geqslant 0 .
\end{aligned}
$$

The inequality holds since $k_{1-c /\left(p^{1}+g^{2}\right)} \geqslant 0$ and $\sigma_{N} \geqslant \sigma_{S}$. Suppose that $\Theta^{-1}\left(1-c /\left(p^{1}+g^{2}\right)\right) \leqslant 0$. Then

$$
\begin{aligned}
-\frac{\partial d_{N}\left(p^{1}, c, g^{2}\right)}{\partial c}+\frac{\partial d_{S}\left(p^{1}, c, g^{2}\right)}{\partial c}= & \mu_{N}+k_{1-c /\left(p^{1}+g^{2}\right)} \sigma_{N}-\mu_{S} \\
& -k_{1-c /\left(p^{1}+g^{2}\right)} \sigma_{S} \\
= & \mu_{N \backslash S}+k_{1-c /\left(p^{1}+g^{2}\right)}\left(\sigma_{N}-\sigma_{S}\right) \\
\geqslant & \mu_{N \backslash S}+k_{1-c /\left(p^{1}+g^{2}\right)} \sigma_{N \backslash S} \\
\geqslant & \sum_{i \in N \backslash S}\left(\mu_{i}+k_{1-c /\left(p^{1}+g^{2}\right)} \sigma_{i}\right) \geqslant 0
\end{aligned}
$$

The first and second inequality follows from $k_{1-c /\left(p^{1}+g^{2}\right)} \leqslant 0$ and (3). The last inequality follows from the assumption that $\mu_{i}+k_{1-c^{2} /\left(p^{2}+g^{2}\right)} \sigma_{i} \geqslant 0$ for all $i \in N$.

$$
\begin{aligned}
-\frac{\partial d_{N}\left(p^{1}, c^{1}, g\right)}{\partial g}+\frac{\partial d_{S}\left(p^{1}, c^{1}, g\right)}{\partial g}= & \sigma_{N} G\left(k_{1-c^{1} /\left(p^{1}+g\right)}\right) \\
& -\sigma_{S} G\left(k_{1-c^{1} /\left(p^{1}+g\right)}\right) \\
\geqslant & 0 \text { for all } g \in\left[g^{1}, g^{2}\right] .
\end{aligned}
$$

The inequality holds since $\sigma_{N} \geqslant \sigma_{S}$. This concludes the proof.

\subsubsection{Dedicated stock levels}

In this section, we study the changes in retailers' dedicated stock levels. We first give examples of a pair and a singleton pair 
of newsvendor games that do not satisfy the monotonicity properties. Then, we focus on a class of newsvendor situations with normal demand distributions and show that pairs of newsvendor games associated with this class satisfy MP1.

The following examples show that in general games associated with newsvendor situations are not guaranteed to have any of the monotonicity properties.

Example 2. Consider two newsvendor situations $\Gamma^{1}=\left(N,\left(X_{i}\right)_{i \in N}\right.$, $\left.\left(c_{i}\right)_{i \in N},\left(p_{i}\right)_{i \in N},\left(g_{i}\right)_{i \in N},\left(\varepsilon_{i}^{1}\right)_{i \in N}\right) \quad$ and $\Gamma^{2}=\left(N,\left(X_{i}\right)_{i \in N},\left(c_{i}\right)_{i \in N},\left(p_{i}\right)_{i \in N}\right.$, $\left.\left(g_{i}\right)_{i \in N},\left(\varepsilon_{i}^{2}\right)_{i \in N}\right)$ such that $N=\{1,2,3\}, c_{i}=1, p_{i}=2, g_{i}=0$ for all $i \in N, \varepsilon^{1}=(1,0,0)$ and $\varepsilon^{2}=(1,1,0)$. The demand of the players are discrete, and independently distributed. The distribution functions are given in Table 2.

The optimal order quantities of the coalitions for both situations are given in Table 3.

Note that order quantity 1 for coalition $\{1,2\}$ in situation $\Gamma^{2}$ is not feasible because of the dedicated stock levels of players 1 and 2. Consider $\Gamma^{1}$ and coalition $\{1,2\}$. Then the value of this coalition can be calculated as follows:

$v^{\Gamma^{1}}(\{1,2\})=-1 * 1+2 * 0.91=0.82$,

where 0.91 is the probability of having a positive total demand. Using similar calculations, we find the values of coalitions presented in Table 4.

Hence, $\left(N, v^{\Gamma^{1}}\right)$ and $\left(N, v^{\Gamma^{2}}\right)$ only differ in the value of coalition $\{1,2\}$. Let $x \in \operatorname{Core}\left(v^{\Gamma^{1}}\right)$. Since $x_{1}+x_{2}+x_{3}=1.718$ and $x_{1}+x_{2} \geqslant 0.82$, we derive that $x_{3} \leqslant 0.898$. Consider the payoff vector $y=(0.4,0.4,0.918) \in \operatorname{Core}\left(v^{\Gamma^{2}}\right)$. Then there is no $x \in \operatorname{Core}\left(v^{\Gamma^{1}}\right)$ such that $x_{3} \geqslant y_{3}$, since $x_{3} \leqslant 0.898$ for all $x \in \operatorname{Core}\left(v^{\Gamma^{1}}\right)$. So pair of games $\left(N, v^{\Gamma^{1}}, v^{\Gamma^{2}}\right)$ (and single deviation pair of games $\left.\left(N, v^{\Gamma^{1}}, v^{\Gamma^{2}}, 1\right)\right)$ does not have MP1 (and MP3).

Example 3. Consider two newsvendor situations $\Gamma^{1}=\left(N,\left(X_{i}\right)_{i \in N}\right.$, $\left.\left(c_{i}\right)_{i \in N},\left(p_{i}\right)_{i \in N},\left(g_{i}\right)_{i \in N},\left(\varepsilon_{i}^{1}\right)_{i \in N}\right) \quad$ and $\quad \Gamma^{2}=\left(N,\left(X_{i}\right)_{i \in N},\left(c_{i}\right)_{i \in N},\left(p_{i}\right)_{i \in N}\right.$, $\left.\left(g_{i}\right)_{i \in N},\left(\varepsilon_{i}^{2}\right)_{i \in N}\right)$ such that $N=\{1,2,3\}, c_{i}=1, p_{i}=2, g_{i}=0$ for all $i \in N$, $\varepsilon^{1}=(0,0,1)$ and $\varepsilon^{2}=(0,1,1)$. Note that player 2 is the deviating player. The demand of the players are discrete and independently distributed. The distribution functions are given in Table 5.

The optimal order quantities of the coalitions for both situations are given in Table 6 . Note that order quantity 1 for coalitions $\{1,2,3\}$ and $\{2,3\}$ in situation $\Gamma^{2}$ is not feasible because of the dedicated stock levels of players 1,2 and 3 . Using similar calculations as in Example 2, we derive $\left(N, v^{\Gamma^{1}}\right)$ and $\left(N, v^{\Gamma^{2}}\right)$ as given in Table 7. Let $y \in \operatorname{Core}\left(v^{\Gamma^{2}}\right)$. Then

$y_{1}+y_{2} \geqslant 0.3$

$y_{1}+y_{3} \geqslant 0.44$

$\sum_{i \in N} y_{i}=0.62$

Adding (4) and (5), we find that $2 y_{1}+y_{2}+y_{3} \geqslant 0.74$. Therefore, using (6), $y_{1} \geqslant 0.12$. Moreover, from (4) and (6), $y_{3} \leqslant 0.32$.

Table 2

The demand distributions (Example 2).

\begin{tabular}{lll}
\hline Player & $x$ & $P(X=x)$ \\
\hline 1 & 0 & 0.3 \\
& 1 & 0.7 \\
2 & 0 & 0.3 \\
& 1 & 0.7 \\
3 & 0 & 0.1 \\
& 1 & 0.9 \\
\hline
\end{tabular}

Table 3

The optimal order quantities (Example 2).

\begin{tabular}{llllllll}
\hline$q^{S, *}$ & $\{1,2,3\}$ & $\{1,2\}$ & $\{1,3\}$ & $\{2,3\}$ & $\{1\}$ & $\{2\}$ & $\{3\}$ \\
\hline$\Gamma^{1}$ & 2 & 1 & 2 & 2 & 1 & 1 & 1 \\
$\Gamma^{2}$ & 2 & 2 & 2 & 2 & 1 & 1 & 1
\end{tabular}

Table 4

The (single deviation) pair of cooperative games (Example 2).

\begin{tabular}{lll}
\hline$S$ & $v^{\Gamma^{1}}(S)$ & $v^{\Gamma^{2}}(S)$ \\
\hline$\{1,2,3\}$ & 1.718 & 1.718 \\
$\{1,2\}$ & 0.82 & 0.8 \\
$\{1,3\}$ & 1.2 & 1.2 \\
$\{2,3\}$ & 1.2 & 1.2 \\
$\{1\}$ & 0.4 & 0.4 \\
$\{2\}$ & 0.4 & 0.4 \\
$\{3\}$ & 0.8 & 0.8 \\
\hline
\end{tabular}

Table 5

The demand distributions (Example 3).

\begin{tabular}{lll}
\hline Player & $x$ & $P(X=x)$ \\
\hline 1 & 0 & 0.7 \\
& 1 & 0.3 \\
2 & 0 & 0.5 \\
& 1 & 0.5 \\
3 & 0 & 0.4 \\
& 1 & 0.6
\end{tabular}

Table 6

The optimal order quantities (Example 3).

\begin{tabular}{llllllll}
\hline$q^{S, *}$ & $\{1,2,3\}$ & $\{1,2\}$ & $\{1,3\}$ & $\{2,3\}$ & $\{1\}$ & $\{2\}$ & $\{3\}$ \\
\hline$\Gamma^{1}$ & 1 & 1 & 1 & 1 & 0 & 1 & 1 \\
$\Gamma^{2}$ & 2 & 1 & 1 & 2 & 0 & 1 & 1 \\
\hline
\end{tabular}

Consider payoff vector $x=(0.02,0.28,0.42)$. It is easy to check that $x \in \operatorname{Core}\left(v^{\Gamma^{1}}\right)$. Since $x_{1}=0.02$ and $y_{1} \geqslant 0.12$ for all $y \in \operatorname{Core}\left(v^{\Gamma^{2}}\right)$, there is no $y \in \operatorname{Core}\left(v^{\Gamma^{2}}\right)$ such that $y \leqslant x$. Hence, the pair of games $\left(N, v^{\Gamma^{1}}, v^{\Gamma^{2}}\right)$ does not satisfy MP2.

Moreover, we know that for any payoff vector $y \in \operatorname{Core}\left(v^{\Gamma^{2}}\right), y_{3}$ $\leqslant 0.32$. Consider payoff vector $x=(0.02,0.28,0.42) \in \operatorname{Core}\left(v^{\Gamma^{1}}\right)$. Since $x_{3} \geqslant 0.32$ and $y_{3} \leqslant 0.32$ for all $y \in \operatorname{Core}\left(v^{\Gamma^{2}}\right)$, we conclude that $x \notin \operatorname{Core}\left(v^{\Gamma^{2}}\right)$ and there is no $y \in \operatorname{Core}\left(v^{\Gamma^{2}}\right)$ such that $y_{3} \geqslant x_{3}$. Note that player 3 is not the deviating player. Therefore, the single deviation pair of games $\left(N, v^{\Gamma^{1}}, v^{\Gamma^{2}}, 2\right)$ does not satisfy MP4 either.

In the remainder of this section, we focus on a class of newsvendor situations such that MP1 is satisfied by the associated class of games. Consider a newsvendor situation $\Gamma=\left(N,\left(X_{i}\right)_{i \in N},\left(c_{i}\right)_{i \in N}\right.$, $\left.\left(p_{i}\right)_{i \in N},\left(g_{i}\right)_{i \in N},\left(\varepsilon_{i}\right)_{i \in N}\right)$ with independent normally distributed demands $X_{i} \sim N\left(\mu_{i}, \sigma^{2}\right)$ for all $i \in N, c_{i}=c$ for all $i \in N, p_{i}=p$ for all $i \in N, g_{i}=g$ for all $i \in N$ and $\varepsilon_{i}=\mu_{i}+k \sigma$ with $k \in \mathbb{R}$ for all $i \in N$. Note

Table 7

The (single deviation) pair of cooperative games (Example 3).

\begin{tabular}{lll}
\hline$S$ & $v^{\Gamma^{1}}$ & $v^{\Gamma^{2}}$ \\
\hline$\{1,2,3\}$ & 0.72 & 0.62 \\
$\{1,2\}$ & 0.3 & 0.3 \\
$\{1,3\}$ & 0.44 & 0.44 \\
$\{2,3\}$ & 0.6 & 0.2 \\
$\{1\}$ & 0 & 0 \\
$\{2\}$ & 0 & 0 \\
$\{3\}$ & 0.2 & 0.2 \\
\hline
\end{tabular}


that with this description, we consider retailers all having identical $c$, $p$ and $g$, non-identical mean demands, and identical variances. This case represents situations where the retailers' forecast errors follow identical independent normal distributions. Moreover, we remark that for all $k \in \mathbb{R}, \varepsilon_{i}=\mu_{i}+k \sigma$ guarantees the same probability of stockout (usually denoted as service measure P1) for each retailer $i \in N$. We denote a newsvendor situation with normal demand (NSND) by $\Pi=\left(N,\left(\mu_{i}\right)_{i \in N}, \sigma, c, p, g, k\right)$. In a NSND, there is no difference in satisfying demands for different retailers in terms of total profit of a coalition because of common purchasing cost and selling price. Therefore, the profit function of coalition $S$ can be written as follows $\pi^{S}\left(q^{S}\right)=E_{X_{S}}\left[-c * q^{S}+(p+g) \min \left\{q^{S}, \cdot\right\}\right]-g \mu_{S}$,

where $X_{S}=\sum_{i \in S} X_{i}$ and $\mu_{S}=\sum_{i \in S} \mu_{i}$. Since $X_{i}$ 's are independent and normally distributed, $X_{S}$ is normally distributed with parameters $\mu_{S}$ and $\sigma_{S}^{2}=|S| \sigma^{2}$. In inventory literature, it is known that $E_{X^{S}}[-c$ $* q+(p+g) \min (q, \cdot)]$ (the profit function of newsvendor problem without any dedicated stock) is a concave function and the optimum $\bar{q}$ maximizing this function satisfies $F_{S}(\bar{q})=1-c /(p+g)$, where $F_{S}$ is the cumulative distribution function of $X_{S}$. Since $X_{S}$ is normally distributed, $\bar{q}=\mu_{S}+k_{1-c /(p+g)} \sigma_{S}$, where $k_{1-c /(p+g)}$ is the unique number such that the standard normal cumulative distribution function $\Theta$ satisfies $\Theta\left(k_{1-c /(p+g)}\right)=1-c /(p+g)$. Since $E_{X^{s}}[-c * q$ $+(p+g) \min (q, \cdot)]$ is concave, it follows immediately that the optimal order quantity of coalition $S$ is the maximum of the optimal order quantity of the newsvendor problem without any dedicated stock and the sum of the dedicated stock levels of the retailers in $S$, i.e., $q^{S}=\max \left\{\mu_{S}+k_{1-c /(p+g)} \sigma_{S}, \mu_{S}+k|S| \sigma\right\}$. Let $\left(N, v^{\Pi}\right)$ be the associated newsvendor game. Then, the profit of coalition $S$ is given by

$v^{\Pi}(S)=(p+g-c) q^{S}-(p+g) \sigma_{S} \int_{-\infty}^{\frac{q^{S}-\mu_{S}}{\sigma_{S}}} \Theta(x) d x-g \mu_{S}$.

The following proposition provides a property of the newsvendor games associated with NSNDs.

Proposition 2. Let $\Pi=\left(N,\left(\mu_{i}\right)_{i \in N} \sigma, c, p, g, k\right)$ be a NSND. Let $\left(N, v^{\Pi}\right)$ be the associated newsvendor game. Then, $\left(N, v^{\Pi}\right)$ is convex if $k \leqslant$ $k_{1-c /(p+g)} / \sqrt{|N|}$.

The following lemma shows a relation for pairs of newsvendor games associated with NSNDs.

Lemma 3. Let $\Pi^{1}=\left(N,\left(\mu_{i}\right)_{i \in N}, \sigma, c, p, g, k^{1}\right)$ and $\Pi^{2}=\left(N,\left(\mu_{i}\right)_{i \in N}, \sigma, c, p\right.$, $\left.g, k^{2}\right)$ with $c /(p+g) \leqslant 1 / 2$ and $k^{1} \leqslant k^{2}$ be two NSNDs. Let $\left(N, v^{\Pi^{1}}\right)$ and $\left(N, v^{\Pi^{2}}\right)$ be the newsvendor games associated with $\Pi^{1}$ and $\Pi^{2}$, respectively. Then,

$v^{\Pi^{1}}(T)-v^{\Pi^{2}}(T) \geqslant v^{\Pi^{1}}(S)-v^{\Pi^{2}}(S)$ for all $S \subset T \subseteq N$.

In other words, if the retailers in an NSND decrease their dedicated stock levels by the same amount, the contribution of these changes to a coalition is increasing in the size of the coalition.

The following Theorem follows directly from Proposition 2, Lemma 3, Theorems 2 and 4.

Theorem 12. Let $\Pi^{1}=\left(N,\left(\mu_{i}\right)_{i \in N}, \sigma, c, p, g, k^{1}\right)$ and $\Pi^{2}=\left(N,\left(\mu_{i}\right)_{i \in N}\right.$, $\left.\sigma, c, p, g, k^{2}\right)$ with $c /(p+g) \leqslant 1 / 2, k^{1} \leqslant k_{1-c /(p+g)} / \sqrt{|N|}$ and $k^{1} \leqslant k^{2}$ be two NSNDs. Let $\left(N, v^{\Pi^{1}}\right)$ and $\left(N, v^{\Pi^{2}}\right)$ be the newsvendor games associated with $\Pi^{1}$ and $\Pi^{2}$, respectively. Then, pair of newsvendor games $\left(N, v^{\Pi^{1}}, v^{\Pi^{2}}\right)$ has MP1. If $|N| \in\{2,3\}$, the condition $k^{1} \leqslant$ $k_{1-c /(p+g)} / \sqrt{|N|}$ is not required for pair of newsvendor games $\left(N, v^{\Pi^{1}}, v^{\Pi^{2}}\right)$ to have MP1.

\section{Conclusion}

In this study, we considered profit division problems arising from situations where multiple retailers can order jointly and allocate their order after demand realization to benefit from inventory centralization. However, this cooperation is subject to some limitations. Being in a cooperation, the retailers may impose dedicated stock levels to prevent themselves from possible unwanted situations. These restrictions can also be motivated by service level constraints.

We studied this problem from a cooperative game theoretical point of view and we especially focused on the core concept. Given a situation, the core concept is quite powerful for predicting the outcome of the cooperative game since it results in all stable divisions of total profit. In this paper, we first investigated core nonemptiness for the newsvendor games with dedicated stock and we showed that these games have non-empty cores. This result is important as it shows that dedicated stock restrictions, as specified in this study, do not affect the existence of a stable profit division. Afterwards, we carried the analysis beyond the single-period structure of the newsvendor situation and investigated what would happen in a dynamic environment where system parameters and restrictions are expected to change. Although the core concept can be powerful in a given situation, it has less to say when the conditions and underlying data of the situation change. To address this issue, we worked with four monotonicity properties regarding core, each reflecting special fairness arguments that the retailers would follow in a new situation. MP1 (MP2) suggests that if the values of the coalitions increase (decrease) because of a change in all retailers' parameters, it is possible to find a new core allocation such that none of the retailers gets less (more) in the new situation. MP3 and MP4 deal with the changes caused by a specific player. The sufficient conditions in Table 1 indicate that the monotonicity notions hold more naturally for games with at most 3 players, but more structural conditions (e.g., convexity) are involved for games with more players. The conditions for MP3 and MP4 are easier to check and valuable to make a case by case analysis.

Afterwards, we identified several classes of newsvendor games where MP1 and MP2 hold. To our knowledge, this is the first study considering the effect of dynamic changes in the environment on the cooperation in newsvendor setting. Our results can be summarized as follows: Regarding the cost parameters, we focused on the newsvendor situations under symmetric cost assumptions and showed that up to 3 retailers MP1 is satisfied under changes in cost parameters $p$ and $c$ regardless of joint demand distribution. For penalty cost $g$, such a result does not hold in general under negatively correlated demand. However, this result extends to games with an arbitrary number of retailers for all cost parameters if demands are independent and normally distributed. Moreover, MP2 is naturally satisfied in these situations. All of these results suggest that MP1 and MP2 are naturally satisfied for a fairly general class of newsvendor situations if the changes are caused by the cost parameters. However, MP1 under changes in penalty costs is sensitive to the correlation structure of demand.

Regarding dedicated stock levels, we show that MP1 is satisfied if the retailers forecast errors follow identical independent normal distribution and they work with similar service levels. Next to this, we provided several counterexamples in which none of the monotonicity conditions are satisfied. Hence, monotonicity properties are sensitive to changes in dedicated stock levels and they are not as naturally satisfied as they do for cost parameters. This implies that in cooperative newsvendor situations priorities have to be selected. Either one puts more emphasis on ending up with a core element, essentially disregarding unfair payoff disturbances as a result of changes in dedicated stock levels, or one should depart from the core concept (as a whole).

A natural follow-up to this work would consequently be to look for solutions (e.g., set-valued or single-valued) that satisfy similar monotonicity requirements. If core-conditions are considered 
equally desirable, this restricts attention to subsets or elements of the core. An alternative direction of research is further refinement of the sufficient and necessary conditions required for monotonicity for the newsvendor situation described here.

\section{Appendix A. Supplementary data}

Supplementary data associated with this article can be found, in the online version, at doi:10.1016/j.ejor.2011.11.021.

\section{References}

Anupindi, R., Bassok, Y., Zemel, E., 2001. A general framework for the study of decentralized distribution systems. Manufacturing and Service Operations Management 3, 349-368.

Bondareva, O., 1963. Certain applications of the methods of linear programming to the theory of cooperative games. Problemy Kibernetiki 10, 119-139 (in Russian).

Chang, P.L., Lin, C.T., 1991. On the effect of centralization on expected costs in a multilocation newsboy problem. Journal of the Operational Research Society 42 , 1025-1030.

Chen, M.S., Lin, C.T., 1989. Effects of centralization on expected costs in a multilocation newsboy problem. Journal of the Operational Research Society 40, 597602.

Chen, X., Zhang, J., 2009. A stochastic programming duality approach to inventory centralization games. Operations Research 57, 840-851.

Cherikh, M., 2000. On the effect of centralization on expected profits in a multilocation newsboy problem. Journal of the Operational Research Society 51, 755761.

Eppen, G.D., 1979. Effects of centralization on expected costs in a multi-location newsboy problem. Management Science 25, 498-501.

Eppen, G.D., Schrage, L., 1981. Centralized ordering policies in a multi-warehouse system with lead times and random demand. In: Schwarz, L. (Ed.), Multi-Leve Production/Inventory Control Systems: Theory and Practice. North-Holland, Amsterdam, pp. 51-69.

Gerchak, Y., Gupta, D., 1991. On apportioning costs to customers in centralized continuous review inventory systems. Journal of the Operations Management 10, 546-551.

Granot, D., Sošić, G., 2003. A three stage model for a decentralized distribution system of retailers. Operations Research 51, 771-784.

Hartman, B., Dror, M., 1996. Cost allocation in continuous review inventory models. Naval Research Logistics Quarterly 43, 549-561.
Hartman, B., Dror, M., Shaked, M., 2000. Cores of inventory centralization games. Games and Economic Behavior 31, 26-49.

Housman, D., Clark, L., 1998. Core and monotonic allocation methods. International Journal of Game Theory 27, 611-616.

Ichiishi, T., 1981. Super-modularity: Applications to convex games and to the greedy algorithm for lp. Journal of Economic Theory 31, 26-49.

Ichiishi, T., 1990. Comparative cooperative game theory. International Journal of Game Theory 19, 139-152.

Lounderback, J.G., 1976. Another approach to allocating joint costs: A comment. Accounting Review 51, 683-685.

Megiddo, N., 1974. On the nonmonotonicity of the bargaining set, the kernel, and the nucleolus of a game. SIAM Journal of Applied Mathematics 27, 355-358.

Müller, A., Scarsini, M., Shaked, M., 2002. The newsvendor game has a non-empty core. Games and Economic Behavior 38, 118-126.

Nunez, M., Rafels, C., 2002. The assignment game: The $\tau$-value. International Journal of Game Theory 31, 411-422.

Özen, U. 2007. Collaboration between multiple newsvendors. Technische Universiteit Eindhoven, Ph.D. Thesis, Eindhoven, The Netherlands.

Özen, U., Fransoo, J., Norde, H., Slikker, M., 2008. Cooperation between multiple newsvendors with warehouses. Manufacturing and Service Operations Management 10, 311-324.

Özen, U., Norde, H., Slikker, M., 2011. On the convexity of newsvendor games. International Journal of Production Economics 133, 35-42.

Robinson, L., 1993. A comment on Gerchak and Gupta's: On apportioning costs to customers in centralized continuous review inventory systems. Journal of Operations Management 11, 99-102.

Sasaki, H., 1995. Consistency and monotonicity in assignment problems. International Journal of Game Theory 24, 373-397.

Shapley, L., 1953. A value for $n$-person games. In: Tucker, A., Kuhn, H. (Eds.) Contributions to the Theory of Games II. Princeton University Press, Princeton, pp. 307-317.

Shapley, L., 1967. On balanced sets and cores. Naval Research Logistics Quarterly 14, 453-460.

Slikker, M., Fransoo, J., Wouters, M. 2001. Joint ordering in multiple news-vendor situations: A game-theoretical approach. Working paper, Technische Universiteit Eindhoven, Eindhoven, The Netherlands.

Slikker, M., Fransoo, J., Wouters, M., 2005. Cooperation between multiple newsvendors with transshipments. European Journal of Operational Research 167, $370-380$.

Sošić, G., 2006. Transshipment of inventories among retailers: Myopic versus farsighted stability. Management Science 52, 1493-1508.

Young, H.P., 1985. Monotonic solutions of cooperative games. International Journal of Game Theory 14, 65-72. 